\title{
SERVITIZATION OF SOUTH KOREA ECONOMY: CAUSES FOR SLUGGISHNESS AND POLICY ISSUES
}

\author{
${ }^{1}$ Bongho Kim and ${ }^{2}$ Seok Yoon \\ ${ }^{1}$ Department of Economics, College of Social Science, Kangnam University, \\ 40 Kangnam-Ro Kiheung-Ku Yongin City, Kyeonggi-Do, 446-702, Korea \\ ${ }^{2}$ College of International Business, Division of Business Administration and Economics, Konkuk University, \\ 322 Danwol-Dong, Chungju-Si, Chungcheonbuk-Do, 380-701, Korea
}

Received 2014-07-29; Revised 2014-08-15; Accepted 2014-09-02

\begin{abstract}
Since the 1960 s, the South Korea economy has achieved a rapid economic growth, whereas from the mid 1990's and beyond, servitization showing the growth of the service section over the nominal GDP has rapidly developed. On the other hand, the service industry productivity declined, even lower than the OECD average. These results continue recently through the deterioration of income inequality. Therefore, the objective of this study is to examine the status and characteristics of the servitization of South Korea economy, analyze the causes for the service industry's productivity slowdown and income inequality. By presenting the policy issues for securing the service industry's competition, this study attempts to define the policy implications to build the framework for economic advancement.
\end{abstract}

Keywords: Servitization, Service Economy, Service Industry, Service Sector, Service Trade

\section{INTRODUCTION}

Since the 1960 s, the South Korea economy has achieved a rapid economic growth, whereas from the mid 1990's and beyond, servitization that shows the growth of the service section over the nominal GDP has rapidly developed. The term economic servitization, referred to as a comprehensive concept combined with goods and services, indicates the phenomenon where the weight of production, consumption and employment increases within the national economy, be means of the service industry showing an increase in production and capital, knowledge intensive trends and the outsourcing of manufacture business services (BK, 2009). In other words, servitization refers to the growth of the tertiary industry accompanied with the growth of the economy.

In South Korea, there was a consistent growth in the service industry with the growth of the economy.
Namely, the growth of the service industry led its market importance from $49.5 \%$ (1990) to 58.2\% (2010) and it enabled an expansion in terms of export and import as well as employment. These developments in servitization are evaluated to be the leading factors in South Korea's economic growth.

However, despite the fact that servitization is the driving force to South Korean's economic development, it is necessary to analyze whether its results are appropriate in terms of economic effects that include income distribution and resource distribution. In other words, if the development in the service industry causes inequality in income distribution and distorts resource distribution, it may not be considered a genuine growth, nor be the desired results with respect to resource distribution, which could not say the country is in a genuinely competitive position with other rival countries.

Corresponding Author: Seok Yoon, College of International Business, Division of International Trade and Culture, Konkuk University, 322 Danwol-Dong, Chungju-Si, Chungcheonbuk-Do, 380-701, Korea 
It is necessary to look into the economic servitization, which simultaneously emerged with the achievement of South Korea's hi-speed economic growth so far, from two perspectives. Firstly, the income inequality has become more severe with the development of the economic structure of servitization. The Gini coefficient, representing the gap between the rich and the poor, demonstrates a value of 0.245 (1992) and 0.295 (2009), which shows in analysis data that servitization has brought about a deepened income inequality, with a growth in service industries contributed to an estimated 32\% (Choi and Park, 2012).

Secondly, according to the recent 2010 Industry Input-Output Table Results presented by (BK, 2014), the manufacturing industry showed an increase from 45.2 to $49 \%$, while the service industry declined from 42.3 (2005) to $40.3 \%$ (2010). Such results may help determine that Korea's future economic productivity slowdown and structural vulnerability may be deepen and result in the weakening of competitive power, when comparing an increase in the average of top 20 OECD nations from 58.1 to $59.4 \%$ to a slight decline of the manufacturing industry, during the same period (Yoon et al., 2012).

Therefore, this study aims at examining the status and characteristics of the servitization of Korea's economy, as well as diagnosing the structural vulnerability and problems regarding servitization. After unveiling the meaning and causes of productivity slowdown, this study intends to present policy issues for setting up the framework for economic advancement by presenting policy assignments for service industry for the following: Enhancing the growth potential for achieving the per capita income increase of 4 million dollars, improvement of service balance, investment promotion and deregulation.

\section{SERVITIZATION STATUS AND ISSUES}

\subsection{Servitization Issues}

\subsubsection{Servitization}

Servitization with respect to an economic structure has been an international phenomenon. It is know that South Korea's economic structure has also quickly progressed in servitization. The world's average additional value of the service industry in GDP was $53.4 \%$ (1970) and $70.9 \%$ (2010), up $17.4 \%$, while the OECD members' average was 55.8 to $74.4 \%$, up $18.6 \%$. South Korea showed an increase from 44.7 to $58.2 \%$, up $13.5 \%$, during the same period of time. But, the speed of the process of servitization over a long period of time is considerably low compared to the world average (Lee and Ha, 2013). However, the data only after the 1990s indicates South Korea recorded an $8.7 \%$ increase, similar to the level of the whole world and OECD countries until 2010, which represents the fact that servitization speed gains more power than the times before the 1990 .

South Korea's servitization by industry also started to grow since the start of the market opening in the mid1995s when the market opening, as shown in Table 1, maintaining its nominal GDP level at 56.8\% (2000), $58.4 \%$ (2005) and 58.2\% (2010).

Among the service industries, GDP of traditional service industries defined as wholesale and retail trade and food and hospitality industry accounts for about $11.2 \%$ (2010). GDP of the knowledge service industry classified into banking, insurance and communication accounts for $25.4 \%$ (2010), which is relatively and respectively below the average of 12.1 and $26.1 \%$ (statistically obtainable) for the 8 OECD countries (U.S.A., France, Germany, Italy, Sweden, Finland, Norway, South Korea) (KITA, 2013). These results show South Korea's servitization has increased after market opening but its industrial structure is formally growing to assume an aspect of the advancement in the industrial structure (Park, 2011).

\subsubsection{Employment and Labor Productivity}

Servitization is a phenomenon that appears throughout the national economy. Therefore, service policies should vary according to what effects servitization has on production, employment and labor productivity, which consist of national economy. The service industry relating to this influences the employment status, subsequent wages and labor productivity. As seen in Table 2 , jobs in South Korea's service industry are far more than the manufacturing and construction industry. It is only service industry that is consistently creating employment opportunities, which is considered to still stay in low productivity and also vulnerable to international competitiveness (IMC, 2013).

That is, Table 2 shows the number in employment by industry indicating employment grows only in the service industry after the early $1990 \mathrm{~s}$. On the other hand, Table 3 shows added value representing productivity grows slower than employment so the gap in the labor productivity per capital with the manufacturing industry and service industry continues to increase. Therefore, the labor productivity of the service industry is about half of the manufacturing industry, as of the year 2011. 
Table 1. Service industry share in total GDP (2010) of major countries

\begin{tabular}{lllllll}
\hline South Korea & U.S.A. & England & Germany & Japan & Switzerland & OECD average \\
\hline $58.2 \%$ & $76.8 \%$ & $77.5 \%$ & $71.3 \%$ & $73.8 \%$ & $71.1 \%$ & $69.5 \%$ \\
\hline
\end{tabular}

Source: Korea international trade association, June 2013

Table 2. Trend of employment by industry (Unit: Ten thousand people)

\begin{tabular}{lrrrrr}
\hline & 1980 & 1990 & 2000 & 2010 & 2012 \\
\hline Service industry & 506 & 844 & 1,295 & 1,638 & 1,718 \\
Manufacturing industry & 308 & 499 & 431 & 414 & 410 \\
Agriculture, forestry and fishery industries, construction industry & 550 & 458 & 382 & 331 & 330 \\
\hline
\end{tabular}

Source: Inter-ministry cooperation, July 2013

Table 3. Labor productivity per capita (Unit: Ten thousand won)

\begin{tabular}{llll}
\hline & 2004 & 2008 & 2011 \\
\hline Service industry (A) & 2,950 & 3,500 & 3,860 \\
Manufacturing industry (B) & 4,930 & 6,470 & 8,510 \\
Manufacturing and service industry ratio (A/B) & 0.60 & 0.54 & 0.45 \\
\hline
\end{tabular}

Source: Inter-ministry cooperation, July 2013

These results show the labor productivity of the service industry was much higher until the late $1990 \mathrm{~s}$, when comparing labor productivity between service industry and manufacturing industry. But, the two sectors reversed in portion and the gap widened as the manufacturing industry's labor productivity improved rapidly. A rise in service industry's labor productivity since the $1990 \mathrm{~s}$ was modest due to an unexpected slowdown when compared to the $1980 \mathrm{~s}$, whereas the manufacturing industry progressed quickly. As shown before, as the advancement and servitization of the industrial structure make progress, the decrease in employment and labor productivity may lead to income inequality.

\subsubsection{Income Inequality}

In a traditional economic theory, human capital gains more importance with the advancement of an industrial, which leads to an increase in income distribution. Income inequality has become more severe worldwide since the $1970 \mathrm{~s}$, which is regarded to have been influenced, on the contrary, by the expansion of the service sector. When it comes to factors where the progression of servitization of the industrial structure may aggravate income inequality, following are presented: The productivity gap between the manufacturing and service industry, the differences in the relative benefit of globalization and liberalization and weakened functions of national income redistribution (OECD, 2011).

Some criticize that South Korea, in particular, is experiencing deepened income inequality as the slowdown in job creation effects from the growth due to productivity in the manufacturing sector leads to more employment opportunities available in service industries bringing many self-employed people and irregular workers.

Income inequality in South Korea showed general improvements before the $1990 \mathrm{~s}$ when the manufacturing industry showed active growth, but it turned for worse since the $1990 \mathrm{~s}$ when the service industry began to grow at trend. This became far worse especially in the late $1990 \mathrm{~s}$ while going through the financial crisis that hit the nation. The Gini coefficient gradually decreased from 0.389 (1980), 0.345 (1985), 0.336 (1988) and 0.310 (1993). However, the Gini coefficient since the 1990s rose from 0.245 (1992) to 0.295 (2009), maintaining 0.289 (2011) (Choi and Park, 2012).

Other income distribution indicators also pointed out that the income inequality since the 1990s has deepened at trend. The income quintile share ratio that divides the $20 \%$ of the population with the highest income by the $20 \%$ with the lowest income has increased from 3.72 times (1990) to 4.97 times (2009) and 4.82 times (2011), while the relative poverty rate representing the population with the income level less than $50 \%$ of the middle income also increased from $7.1 \%$ (1990) to $12.4 \%$ (2011).

The imbalance in income distribution can be examined through many economic aspects, but can also be identified by the difference in labor productivity and the subsequent wage gap between the service industry and the manufacturing industry. As with developed countries, South Korea is also considered to see negative 
effects on income distribution caused by the growing number of self-employed people based on service industries due to change in economic structure, such as servitization (Kang, 2012).

\subsubsection{Import and Export Service Profit Due to Openness}

The international discussion regarding the economic servitization and trade openness began to be tabled through the GATT service trade discussion in 1986 UR negotiation. Since then, the discussion on the service industry has begun comprehensively implemented in the General Agreement on Trade Service (GATS) under the WTO system.

Therefore, with the development of openness, there has been a tremendous increase in the import and export of the service trade. The world commodity trade is worth about $\$ 30.6$ trillion (2010) while the service trade of $\$ 7.2$ trillion worth, accounting for about $23.5 \%$. The growth rate of the world service trade had an average annual of $7.4 \%$ in the $1990 \mathrm{~s}$, but rapidly increased to $10.0 \%$ in the $2000 \mathrm{~s}$, similar to a rise in the commodity trade. The expansion of world service trade is caused not only by the increase in the importance of the knowledge-based economy in 2000, but also by the progression of the economic servitization combined with the manufacturing and service industry.

Along with these growth trends, the annual average of South Korea's service trade rose $10.5 \%$ after the year 2000 , but the service trade balance continues to be in a state of fundamental deficit. Also, the scale of the service trade merely ranks 15 in the world, in comparison with the manufacturing industry ranking at 7 th position, should call for a need to have a competitiveness in the future and make efforts to grow export volumes.

In particular, Table 4 shows a surplus by sector in such fields as building, transportation and finance, while business service, travel and intellectual property rights suffer deficit trends.

\subsubsection{Service Industry Regulations}

Analysis findings of a total of 7,700 registered regulations (main regulations) listed on the Regulatory Reform Committee, as of February of 2014, showed the number of regulations on the service industry numbered 4,336 , while the number of regulations on the manufacturing industry reached 1,073. As long as common regulations are excepted, the regulations applicable only to the manufacturing industry merely numbered 338 while service industry regulations reached 3,601 (RRC, 1998).
The number of registered regulations by sector, as seen in Fig. 1, showed the number of regulations on the service industry reached 10 times more than the manufacturing industry. Besides, regulations over the five core sectors announced by the government to foster intensively, such as healthcare, education, tourism, finance and software reached half of the entire service industry regulations.

Due to such excessive regulations, the government's guidelines for fostering the service industry are on the right track for the continuous growth of the South Korean economy. It is regarded that one of main reasons why the measures to nurture the service industry attempted as many as 20 times in years past have not been more than expected, is that deregulation was not implemented properly due to social conflicts. Furthermore, evaluations regarding such regulations caused the government to announce at the 2014 New Year's press conference that it should implement deregulation to promote the service industry. In this respect, public attention is called as to whether such excessive regulations over the service industry will be eased or not.

\subsection{Servitization Issues and Causes for Sluggishness}

As examined previously, there was a progress of servitization in terms of the process of South Korea's economic growth. Briefly speaking, however, the servitization of South Korea's economy continued to develop, whereas the servitization in the manufacturing industry turns out to be relatively sluggish.

Results of the international comparison of the service input coefficients that come up in the process of servitization show that Korea along with Mexico and China is far behind main OECD countries in terms of the servitization of the manufacturing process particularly in the manufacturing industry (Lee, 2013). Namely, South Korea is considered more vulnerable than advanced countries to the relationship where the production from the manufacturing industry promotes the service input which again prompts the growth of the service industry.

\subsubsection{Servitization Issues}

The issues South Korea economy has faced in the course of its economic growth and servitization are examined from the following two broad perspectives: Firstly, some point out that the service industry has continually created jobs thanks to the number of people employed, with the productivity at a low level. 


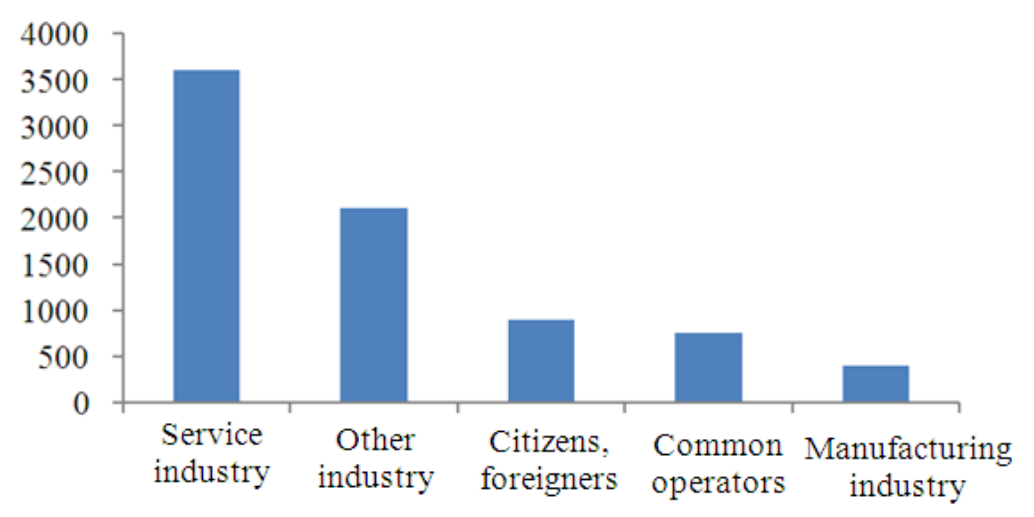

Fig. 1. Number of registered regulations by sector (Based on February, 2014) (Unit: Number) Source: Regulatory reform committee; http://www.better.go.kr

Table 4. Service balance by sector (Unit: \$100million)

\begin{tabular}{lrrrrrr}
\hline & 90 & 95 & 00 & 05 & 10 & 12 \\
\hline Service balance & -5 & -27 & -28 & -137 & -183 & -141 \\
Transportation & -8 & -3 & -36 & 37 & 93 & 105 \\
Business service & 3 & 9 & -31 & -61 & -135 & -152 \\
Intellectual property rights & -13 & -20 & -25 & -26 & -58 & -49 \\
Travel (education) & 4 & $-12(-9)$ & $-3(-9)$ & $-96(-33)$ & $-84(-44)$ & $-58(-43)$ \\
\hline
\end{tabular}

Note: Excludes the construction balance (not included in the industrial classification) from the international balance statistics.

Source: Inter-ministry cooperation, July 2013

The servitization of a manufacturing process in economy, particularly, the degree of servitization of the manufacturing process in the manufacturing industry, has a relatively high correlation with a nation's level of economic development. Therefore, an ongoing economic development raises a growing need to employ service functions by means of efficiency improvements in the manufacturing industry, new product development, high performance and high added value of existing products.

However, the servitization of South Korea's economy sees productivity slowdown conversely aggravate the service balance regarding import and export in the service sector, which is unable to reflect the effect of creating more jobs than the manufacturing industry. This results in lowering the added value and causing the weakened international competitiveness of the entire service industry, being emerged as a big problem with the recovery of South Korea's competitiveness.

Secondly, the servitization of South Korea's economy is causing income inequality. In a traditional economic theory, income inequality can be caused not only by a change in the industrial structure, but also by various social and economic factors, such as labor market conditions, technological advances, inflation and government policies. The income inequality of South Korea's service industry is proved to have a large gap in income distribution as the Gini coefficient indicators representing income distribution show an increase while servitization is being present. The research results of the empirical analysis show the increased proportion of the service industry, which takes the Gini coefficient as an explained variable, presents statistically significant consequences (Choi and Park, 2012).

The real big problem is that such deepened income inequality ripples into the manufacturing industry and finally affects the entire economy, causing an economic depression and competitiveness weakening.

\subsubsection{Causes for Sluggishness}

As mentioned previously, causes for low productivity and income inequality in South Korea's service industry are pointed out. Firstly, the following are the causes for low productivity:

- Foundations for service industry development became vulnerable because of the firm establishment of export-focused economic system led by the manufacturing industry following the 
economic development alliance, in terms of economic and industrial systems. The manufacturing industry, on the other hand, actively pursued opening doors to foreign countries and overseas expansion strategies, successfully enough to create sustainable growth and added value, whereas the service industry results in failing to secure global competitiveness due to primary in-house corporate activities content with domestic market

- With respect to the structural aspect of the service industry, traditional service sectors, such as food and hospitality and retail wholesale services, have lowered entry barriers and contribute to fixing the manpower surplus structure where the majority are livelihood-type self-employment. This enabled the manufacturing industry to feature high added value and less working hours, with the service sector featuring low added value and many working hours, which caused competitiveness

- With respect to building infra in the service industry, a well-organized education training system for the creative service workforce is insufficient and a culture of paying the reasonable price due to the lack of recognition to the service. This studys as causes for corporate profitability worsening in the short term and corporate competitiveness weakening in the long term

Secondly, according to the estimation, income inequality is caused by the fact that the service industry has lower labor productivity than the manufacturing industry, the ripple effect of the manufacturing industry is low when the in-house labor productivity gap is high, yet the service industry sees employment expansion under way, which therefore deepens the income inequality.

\section{DEVELOPMENT DIRECTIONS AND POLICY ISSUES IN SERVICE INDUSTRY}

\subsection{Limitations as Measures for Service Industry}

Policies for South Korea's service industry development have been implemented about 20 times, in total, in the last 5 years. Implementing promotion measures for the service industry brings a success to such fields as tourism, health and medical care and education, but there is also a criticism that in many cases the parties concerned between individual economic players have conflicting interests which consequently brings insufficient outcomes.

Comprehensive measures for the service industry in the past 5 years are so called measures for advancement (IMC, 2012a). That is, comprehensive measures for the service industry may include foreign expansion methods and sector-specific measures. As for comprehensive measures, they are designed to concretely seek opportunities for South Korea businesses in the service sector to step into foreign markets by easing regulations of many kinds, whereas sector-specific measures deal with preparing and implementing separate measures between segmented industries in each government division. This applies to each sector as shown in the examples: (i) The tourism sector improve the visa system to attract foreign tourists. (ii) The health and medical care sector reduces the regulations by allowing convenience stores to sell some medical supplies causing no management issue in terms of safety. (iii) The education sector expands free economic zones for more international schools or foreign educational institutions to be founded. (iv) The broadcasting or advertisement sector also outlines main initiatives such as introducing the competition structure (KDI, 2013).

Main policies on South Korea's service industry have been implemented so far through deregulation following the market opening. Speaking of the limitations for performances until now, considerable number of policies or initiatives fails to reach an agreement for system improvement or become a law due to conflicting interests, being remained as a delayed case in system improvement.

\subsection{Directions for Service Industry Development}

To properly achieve development goals planned and implemented up to the present in the service sector, steady and continuous measures are needed, rather than piecemeal measures. In addition, known successful case studies are needed to be gathered and shared and the government primarily needs to move forward with tasks with a low social conflict level, simultaneously creating a consensus as a conflict resolution task. Government-led policies may need to be performed through full consultations with businesses, consumers, local community groups, related professionals and the national assembly.

Basic directions for service industry development the government has announced recently for initiatives and fresh start are shown in Fig. 2 below. 
Kim and Yoon / American Journal of Applied Sciences 11 (9): 1692-1702, 2014

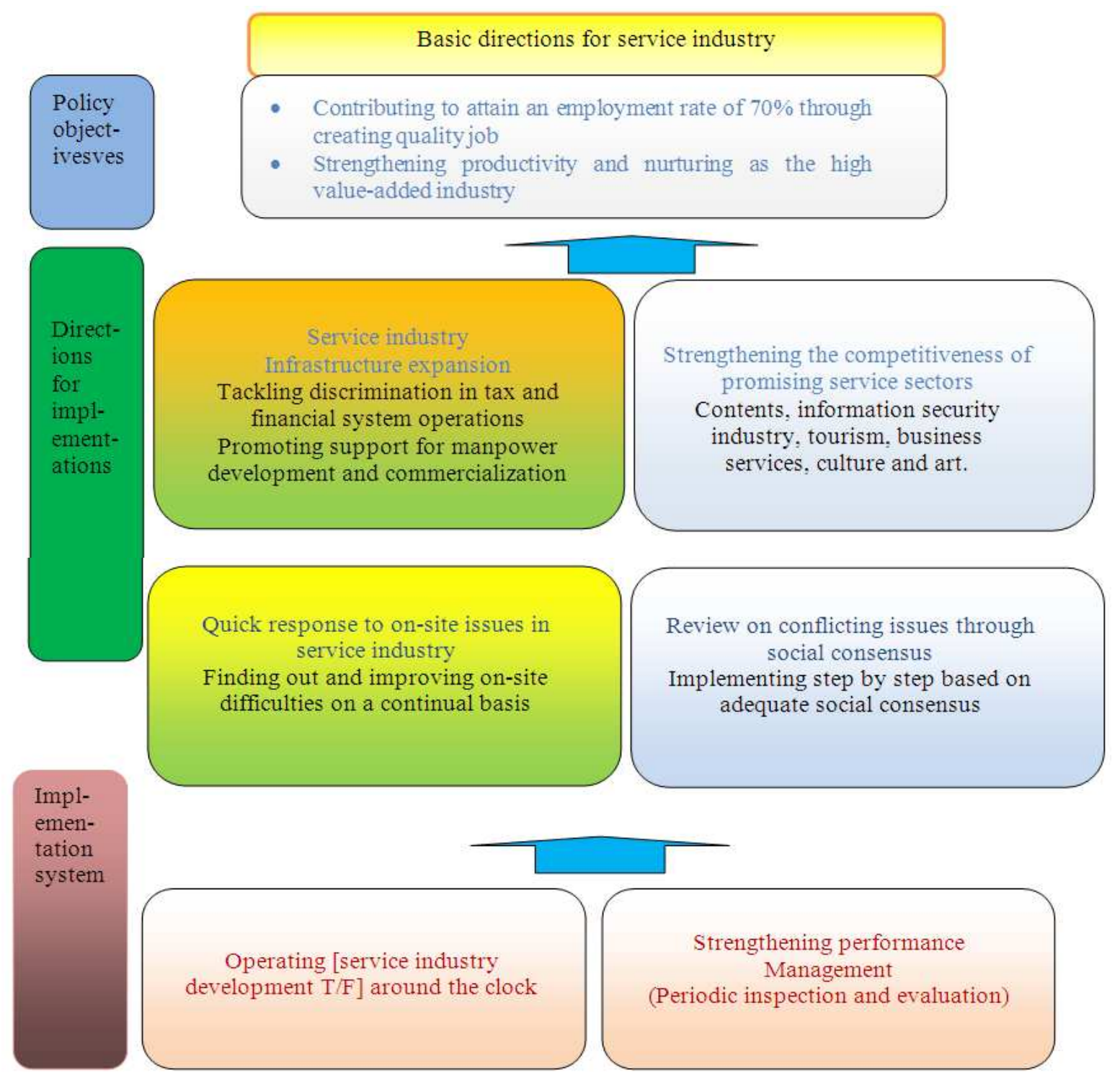

Fig. 2. Basic directions for service industry development source: Inter-ministry cooperation, July 2013

\subsection{Policy Issues}

What was examined so far includes the present status, issues and causes for sluggishness regarding South Korea's service industry. South Korea's servitization has rapidly risen following the market opening but is still lower than the OECD average, being evaluated to stay behind competitiveness with respect to even labor productivity or added value.

Therefore, in order for the government to secure competitiveness of the service industry, it should move forward with concrete policy goals and tasks to make the industry more productive and higher in added value. Based on the issues and causes for sluggishness of the service industry examined until now, this study intends to propose system supplementations for productivity improvement and policy tasks that can correct income inequality, as well as policy tasks as basic directions for driving policies being implemented by the government (IMC, 2013).

The following are necessary basic directions for policy implementations as shown in Fig. 2: (i) 
Eliminating discrimination inherent in the economic system against the service industry and continuing to expand the service industry's infrastructure such as supporting the manpower development and commercialization. (ii) Pursuing the strengthening of competitiveness by sector based on promising service industries for high added value according to selection and concentration strategy. (iii) Quick to resolve onsite difficulties raised by industrial associations and enterprises through constant inter-ministry collaboration systems. (iv) Coming up with development plans, on a step-by-step and continual basis, instead of piecemeal basis.

\subsubsection{Measures for Productivity Improvement and Infrastructure Expansion}

The service industry is a key sector to support South Korea's sustainable economic growth by leading the domestic demand expansion and job creation simultaneously. Therefore, increasing productivity in the service sector is a prerequisite to strengthening the competitiveness of the service industry, above all. Service Industry Advancement, announced by the government, as well as the productivity improvement should continue to be constantly implemented on a mid-to long-term basis. While the service industry, owing to its unique characteristic, is made up of mostly intangible properties such as knowledge and manpower, the current tax and financial systems are operated primarily with tangible properties. This brings discrimination against the service industry so constant improvement efforts are needed.

Firstly, the service industry subject to tax benefits need to be expanded as the elimination of the discrimination in taxation against the service industry and tax benefits should also be provided to the research and development sector, especially to the small-sized research and development service sector. Furthermore, for such reinforced supports to produce synergy, existing manufacturing-based guarantee and export financing support should evaluate the status of the financial institution in support of the service sector situation as part of building a financial assistance system in consideration of the characteristics of the service industry. On top of this, eliminating discrimination should be made so that a new financial assistance system that reflects the characteristics of intangible propertybased service industry can be built.
Secondly, an awareness of the service industry should be encouraged in the course of system operation. For discrimination improvement, efforts should be made to expand occupations and number of applicants for selection for more skilled workmen across South Korea to join the service sector, plus extended support should be provided for skilled workmen and private skills contests through broadcasting and lectures.

Thirdly, it is necessary to nurture human resources and extend vocational education in the service sector. Hence, the service sector should build a variety of service manpower nurturing systems so that outstanding talents can enter the service sector in the mindset that man is a core facility and resource.

For improvement initiatives, manpower nurturing systems should be built with a focus on the convergence field of the service industry in consideration of the youth, the incumbent, the unemployed and the retirees. This should be done in a reorganizing way where the youth should be able to cope effectively with the ever-changing industrial demand through the specialization of the Meister High School, Vocational High School and Polytechnic Colleges and universities. For incumbents, more entrepreneurial universities providing educational training should be founded, whereas re-employment support programs for unemployed and retired people should involve the development of a vocational skill development program in earnest.

Fourthly, support for business start-ups and commercialization in the industry sector should be expanded. Most of all, research and development results should be supported and commercialized for the youth with excellent ideas to be able to start businesses and commercialize them. Concrete policy issues to make it work should include supporting the early stage of commercialization of an idea, increasing support for initial business start-up and integrated facilities to create synergy, as well as extending support for commercializing performances for service technology development.

\subsubsection{Elimination of Income Inequality}

To eliminate income inequality, overall labor productivity in the service industry should be improved, which was suggested previously and the wage gap within the service industry should be 
eliminated. It is desirable to let finance, insurance, information and tele-communication industries with relatively high labor productivity lead productivity and wage active globalization. On the other hand, business service, culture and entertainment and education service business, which are highly likely to grow but still remains insufficient in labor productivity, should encourage productivity and income levels through deregulation and market opening (Kim, 2013). In addition, it is desirable that wholesale and retail trade, food and hospitality, which are relatively low in labor productivity, push for business method improvements such as cost savings by operating a joint business and business size expansion through commercialization.

\subsubsection{Eliminating On-Site Difficulties in Service Industry}

To quickly resolve on-site difficulties in the service industry and bring up performance in the short-time period, customized measures such as deregulation, financial support and system improvement should be prepared. That is, it means expanding service procurement products to help businesses participate in public procurement easily and new venture service businesses should be encouraged for an active participate in public procurements. Flexible operation should also be implemented to support foreign education and research institutions, expanding more investment.

\subsubsection{Measures for Service Industry-Centered Domestic Demand Expansion}

The government's measures for domestic demand expansion is mainly for the manufacturing industry, providing a temporary reduction of individual consumption tax for cars and high-end appliances. But, a need arises as to system supplements to expand service $\mathrm{R}$ and $\mathrm{D}$ for a greater demand by businesses or consumers for the service industry (Park, 2013). This enables development through attracting foreign investments into the service industry by means of reducing regulations on the entry of foreign investments into the service sector, so as to secure core competitiveness, such as brand and know-how in the service industry. Discriminatory factors should also be improved (IMC, 2012b).

\subsubsection{Institutional Supplements for Service Industry Development}

The Service Industry Development Act, which is currently pending in the National Assembly, should be enacted as soon as possible to handle various service sectors and foster the service industry systematically. In other words, it is necessary to prepare the driving system for breakthrough development of the service industry and reinforce the service industry infrastructure. It is also necessary, on the other hand, to build a foundation for the service industry to evolve into a driving force in South Korea's economy (KASI, 2013).

\section{MATERIALS AND METHODS}

This study referred to existing research findings and many literary works related to the servitization of South Korea's economy. Furthermore, the comparative analysis into various statistical data released by the government and presentation materials from the OECD were used to compare and analyze the service industry by country.

Also, causes and points at issue as to why the service industry remains relatively underdeveloped on the basis of the assessment of government policy implementations. This study also presents policy and institutional tasks to supplement required for South Korea to attain its advanced service industry.

\section{RESULTS AND DISCUSSION}

The research findings of this study are as follows: Firstly, the rapid servitization of South Korea's economy brought about productivity slowdown. Secondly, income inequality has deepened over recent years. These results can be seen from the relative comparison between South Korea and OECD nations. Thirdly, the service industry turned out to fail to secure global competitiveness due to business activities mainly done in-house and content in the domestic market. These findings are identically confirmed in the publication by Yoon et al. (2012). Lastly, corporate profitability turned out to suffer a reduction due to lack of education and training for manpower development, and insufficient recognition to development.

Then, how can side effects from servitization be reduced? The focus of the discussion is on diagnosing the policies enforced by the government and making efforts to reduce the subsequent gap generated. 
Besides, the government should intensively nurture specific promising service industries or secure competitiveness through providing financial support. The government has recently announced policies with concrete plans highlighting the strengthening of the service industry competitiveness through such feedbacks. (IMC, 2014) Growing expections are arising as to these service industry investment boosting programs.

The goal of South Korea's economy or governement-driven policy implementations, over recent years, is to turn the economy into the advanced system. Most of all, opening service market overseas and overseas expansion belong to institutional complementary tasks for making the service industry system advanced, whereas nationwide policy implementations for improving productivity and income inequality include deregulation, educational training and system maintenance. The prevailing view is that such tasks should be implemented on the basis of policy.

\section{CONCLUSION}

Progress in servitization is recognized to have been the advanced industrial structure emerging as the economy develops. Therefore, progress in servitization does not necessarily work unfavourably to productivity improvement or income inequality. South Korea's labor productivity in the service industry is generally lower than the manufacturing industry. Income inequality is estimated to have deepened while the employment in the service industry is making progress, as more employment opportunities become available under the circumstances where labor productivity gap is large even within the industries and the ripple effect in employment thanks to the growth in the manufacturing industry does not take effect properly.

On top of this, South Korea's servitization of this nature is relatively lower in productivity and also dropping in added value ratio, when compared to OECD nations. Therefore, what South Korea primarily needs to secure competitiveness in the service industry is active policy support or institutional complements.

As previously examined, the status and issues on South Korea's servitization were presented together with the diagnosis of causes for its sluggishness and policy tasks. The key to these policy issues is to improve the service sector productivity and eliminate income inequality and secure the fundamental competitiveness of the service sector, after all. Therefore, the policy implications to resolve these fundamental problems and develop the service industry, is to reduce regulations through discrimination elimination, market opening, import/export support, service research and development, nurturing workforce by educational training, creating law capable of improving on-site difficulties and supplementing institutional inertia.

\section{ACKNOWLEDGEMENT}

This research was supported by Kangnam University research grants in 2013.

\section{REFERENCES}

BK, 2009. Status of South Korea's Service Industry. Bank of Korea.

BK, 2014. 2010 Industry input-output table results. Press Release. Bank of Korea.

Choi, I.B. and S.W. Park, 2012. Implications regarding income inequality in ongoing servitization of the economic structure. Bank of Korea.

IMC, 2012a. 2012 Implementation plans for service industry advancement. IMC.

IMC, 2012b. Measures for reducing service industry discrimination.

IMC, 2013. Directions for implementing service industry policies and step 1 measures.

Kang, J.G., 2012. Analysis of the causes for expanded income inequality using panel data by country. Economic Analysis. Bank of Korea.

KASI, 2013. Policy proposals for development of the service industry. The Korea Association of Service Industries.

KDI, 2013. On-site case studies and policy recommendations for service industry development. Korea Development Institute.

Kim, C.B., 2013. Regulatory status and tasks for the service industry. Korea Economic Institute.

KITA, 2013. Status of Korea's servitization by international comparison. Korea International Trade Association.

Lee, G.W. and B.C. Ha, 2013. Research of servitization's impact on the structure of associated industries of Korea. Korea Institute for Industrial Economics and Trade. 
Lee, G.W., 2013. Transition and implications of South Korea's economic servitization viewed in the manufacturing process. E-KIET Industrial Economic Information, Industry Research Institute.

OECD, O., 2011. Divided we stand: Why inequality keeps rising?

Park, J., 2011. Analysis of the effects of service export on national economy, trade focus. Korea International Trade Association.
Park, J.S., 2013. Strategic tasks of service industry for realizing creative economy. Industry Research Institute.

RRC, 1998. Greetings. Regulatory Reform Committee.

Yoon, S., Y.D. Kim and K.S. Lee, 2012. International competitiveness of Korea service industry. Am. J. Applied Sci., 9: 343-349. DOI: 10.3844/ajassp.2012.343.349 